\title{
Individual trophic specialisation in the Alpine newt increases with increasing resource diversity
}

\author{
Sebastiano Salvidio*, Andrea Costa \& Federico Crovetto \\ Dipartimento di Scienze della Terra dell'Ambiente e della Vita (DISTAV), Università di Genova, Corso \\ Europa 26, IT-16132 Genova, Italy (*corresponding author's e-mail: salvidio@dipteris.unige.it)
}

Received 19 Sep. 2018, final version received 14 Nov. 2018, accepted 16 Nov. 2018

Salvidio S., Costa A. \& Crovetto F. 2019: Individual trophic specialisation in the Alpine newt increases with increasing resource diversity. - Ann. Zool. Fennici 56: 17-24.

Dietary studies suggest that amphibians are opportunistic predators. However, there is little information on the ability of individuals to change their feeding strategy in time because most studies do not evaluate prey availability and its effect on individual behaviour. To better understand how variation in prey availability may affect the feeding strategy of newts, we studied the Alpine newt, Ichthyosaura alpestris, during April and June in 2015, when we monitored prey availability and the species dietary habits. In April at low prey diversity, the newts were generalists, i.e., their diet overlapped almost completely with prey availability. In June when prey diversity was high, the newts became specialists. At the individual level, 9 out of 15 recaptured newts shifted from a generalist to a specialist feeding strategy from April to June, suggesting a rapid behavioural change in response to increasing prey diversity, in accordance with optimal foraging theory. These results stress the importance of sampling the same individuals several times during an extended period of time to better understand the patterns of diet variation in amphibians.

\section{Introduction}

Populations of generalists are often composed of specialized individuals having a reduced niche as compared with the one representative for the entire population (Bolnick et al. 2002, 2003, Araujo et al. 2011). In the case of a trophic niche, the contribution of specialized individuals to the overall feeding strategy can be estimated by analysing dietary habits of an adequate number of individuals sampled exactly at the same time (i.e., cross-sectional analysis), or by resampling the same individuals at different times. Both methods allow to better understand the impact of individual behaviour on the popu- lation realized trophic niche and have been used to study different species of predators acting at different levels of the food chain (e.g., Bolnick et al. 2002, Araujo et al. 2011, Novak \& Tinker 2015, Pagani-Núnez et al. 2016).

Trophic specialization at the individual level is well recognized in many animal species and has been detected in several post-metamorphic amphibian populations (e.g., Araujo et al. 2009, da Rosa et al. 2011, Schriever \& Williams 2013, Costa et al. 2015, Salvidio et al. 2015). Adult amphibians are generally considered opportunistic predators that feed on many different prey taxa, usually in proportions similar to those in the environment (e.g., Solé \& Rödder 2010). In 
any case, environmental conditions and available prey are not constant trough time, and behavioural responses may change accordingly, both at the population and at the individual levels (Devictor et al. 2010, Pagani-Núnez et al. 2016). Therefore, the population's feeding strategy should be evaluated in time, possibly considering the behavioural response of the same individuals, in particular to assess how constant their individual trophic response to changing prey resources is. However, in the case of Amphibians, only cross-sectional studies were performed to understand the contribution of an individual to the overall population feeding strategy (e.g., Araujo et al. 2009, da Rosa et al. 2011, Schriever \& Williams 2013, Costa et al. 2015, Salvidio et al. 2015), while studies over extended periods of time are still lacking. This lack of information is probably caused by the small size and cryptic behaviour of many amphibians that are difficult to observe in the wild. In addition, recapturing and recognizing amphibian individuals may be challenging and time consuming, although natural patterns can be exploited and several artificial marking techniques, with low impact on animal health and well-being, are now available (Ferner 2010).

To fill this gap, in April and June 2015 we gathered data for a wild newt population living in a simplified habitat. In the present study we sampled an Alpine newt population breeding inside a tank holding water for irrigation. In this natural "mesocosm", we sampled the newts and their available trophic resources two times during the same breeding season, to understand short-term variations in population feeding strategy in relation to the changes in prey availability. First, we investigated how temporal variation in prey availability affects newt foraging behaviour, both at the population and individual levels. In case of a significant variation in prey diversity, we expected that the newts would become more specialized in agreement with the classical theory of optimal foraging strategy (Stephens \& Krebs 1984). Second, we studied potential differences in individual feeding strategies between male and female newts during their breeding season. Here we expected some variations in feeding behaviour to exist between males and females, because intersexual dietary differences were observed in a population of the Alpine newt, sampled in the Czech Republic during the breeding period (Kopekỳ et al. 2012).

\section{Material and methods}

\section{Study species and site}

The studied Alpine newt population belongs to the Italian Apennine subspecies Ichthyosaura alpestris apuanus. This subspecies is found in Italy and is distributed from the Maritime Alps to the Central Apennines, and from the sea level up to about $1800 \mathrm{~m}$ a.s.l. (Andreone et al. 2007). During the aquatic phase, the species' diet includes mainly benthic and planktonic invertebrates, terrestrial invertebrates that fell on the water surface, and also amphibian eggs (e.g., Fasola 1993, Schabetsberger \& Jersabek 1995, Denoël \& Andreone 2003). The diet composition in different populations indicates high variability related to habitat, season and morph type (larvae, pedomorphs and metamorphosed adults) (Fasola 1993, Schabetsberger \& Jersabek 1995, Denoël \& Andreone 2003,Vignoli et al. 2007, Sánchez-Hernández 2014). In particular, adults are usually found along pond shores and near the water surface where they prey opportunistically on terrestrial invertebrates (Denoël et al. 2004, Vignoli et al. 2007). Regarding differences in the diet between sexes, recent studies gave contrasting results. For instance, Lejeune et al. (2018) analysing both stomach contents and stable isotopes showed no differences between male and female diets in the French Alps, while Kopeky et al. (2012) found that, in a Czech Republic population, females consumed more prey items and more prey categories than males. However these results are not mutually exclusive, because the two studied ecosystems were very different and, in addition, the Czech population was sampled during its entire breeding period (Kopeky et al. 2012), while the French one only at the end of its reproductive season (Lejeune et al. 2018).

Our study site is located $300 \mathrm{~m}$ a.s.l. in the municipality of Santo Stefano Magra, Province of La Spezia, Liguria (NW Italy). In the study area, the Alpine newt breeds in natural and artificial standing waters during spring (Andreone 
\& Doré 1992, Andreone et al. 2007), and in rural landscapes this amphibian is often found in tanks holding water for irrigation (Romano et al. 2014). At our study site, there is a tank holding water for irrigation whose dimensions (length $\times$ width $\times$ height) are approx. $3 \times 1.5 \times$ $1 \mathrm{~m}$. The water to fill the tank is drawn from a nearby stream: newts occur both in the stream pools and in the water tank but are more abundant in the latter. In Mediterranean permanent water habitats, paedomorphic populations of the Alpine newt are sometimes present (Andreone et al. 2007), but they were not observed at the study site. Therefore, our study was based only on adult metamorphosed newts.

\section{Sampling and data analysis}

Newts were sampled on 26 April and 4 June 2015. Their diet was evaluated by stomach flushing (Fraser 1976), a non-lethal and highly reliable technique in amphibians and in particular in salamanders (Crovetto et al. 2012, Costa et al. 2014). Flushed animals were immediately released, and no mortality was observed. Newts were sexed on the basis of their secondary sexual characters, such as the presence of a dorsal crest, and blue colouration in adult males (Andreone et al. 2007). In addition, the spotted gular pattern typical for this subspecies (Andreone et al. 2007) was photographed to allow for later individual recognition. Stomach contents were preserved in the field in $70 \%$ ethanol and later analysed under a dissecting microscope in the laboratory. In addition, prey categories available to the newts were sampled in both months by taking six macro-invertebrate samples from the water tank. Invertebrates were collected into a plastic pipe $40 \mathrm{~cm}$ in diameter and $80 \mathrm{~cm}$ long placed on the bottom of the tank bottom using a Surbersampler-like net with a $20 \times 20 \mathrm{~cm}$ quadrat frame and $0.5 \mathrm{~mm}$ mesh. Collected macroinvertebrates preserved in the field in $70 \%$ ethanol and later identified in the laboratory.

Individuals with empty stomachs, or with only plant or unindentifiable animal material were excluded from analyses. In addition, stomachs containing only one identified prey item were also removed, to reduce inflation of the indexes of individual specialization (Bolnick et al. 2002).

We compared the overlap between the population diet and prey availability by means of Pianka's symmetric index (Pianka 1973). This index $\left(O_{j k}\right)$ varies from 0 when there is no overlap, to 1 when a complete overlap occurs. The numbers of prey items available to the newts and sampled in April and June were compared using a binomial test (Siegel \& Castellan 1988).

The diets of the newts sampled in April and June were compared using two-way non-parametric multivariate analysis of variance based on the Bray-Curtis dissimilarity index and 9999 permutations (PERMANOVA; Anderson 2001). Diversity of available prey and of the newts' total niche width (TNW), as defined by Roughgarden (1972) were estimated using Shannon's $H^{\prime}$ with $95 \%$ confidence intervals obtained by 999 permutations. The individual level of specialization was estimated by means of the proportional similarity index (PSi) that measures the overlap between the niche of individual $i$ and the niche of the entire population (Bolnick et al. 2002, 2003). The PSi varies from near 0 , when the individual's niche overlaps little with that of the entire population, to 1 when a complete overlap is observed. The overall population level of specialization was measured using the individual specialization (IS) index, that is the mean of the PSi individual values (Bolnick et al. 2002, 2003). Therefore, a population can be considered specialist when IS assumes low values and generalist when IS approaches 1. Statistical significance of the PSi and IS was assessed by comparison with the null model distribution obtained by 999 Monte Carlo resamplings, in which each individual is reassigned its original number of prey, drawn randomly from the overall dietary sample. To interpret the change in feeding strategy from April to June, we defined the threshold value for a specialist feeding strategy as the lower $95 \%$ limit of the confidence interval of the null distribution derived from 999 Monte Carlo resamplings of the original data set (Costa et al. 2015).

Trophic indexes and null models were estimated using the IndSpec 1.0 software (Bolnick et al. 2002). PSi values and numbers of prey items obtained in April and June for the same 
photo-identified individuals were compared by means of Wilcoxon's paired test, that is suited for comparing the same individuals exposed to different conditions without assuming any $a$ priori distribution (Siegel \& Castellan 1988).

\section{Results}

Newts' eggs were present in the stomachs both in April and June, confirming that sampling covered the entire breeding season. We found both aquatic and terrestrial prey categories in the newts' stomachs indicating that Alpine newts fed opportunistically this kind of prey. The overlap between the population diet and prey availability was almost complete in April $\left(O_{j k}=0.94\right)$, while in June it was reduced $\left(O_{j k}=0.63\right.$; Table 1$)$.

There was no significant difference between April and June population niche widths (April $\mathrm{TNH}=2.01 v s$. June $\mathrm{TNW}=2.16 ; p=0.369$, after 999 permutations). However, there was a significant difference between the months when prey taxonomic composition was considered (PERMANOVA: $F=9.6, p=0.001$ ), with no significant differences for the sex $\times$ month interaction $(F=1.04, p=0.09)$ or between $\operatorname{sexes}(F=$ $1.4, p=0.18$; Table 2).

Table 1. Prey availability and items found in stomachs of newts in April and June. Shannon's diversity index $H^{\prime}$ corresponds to the total niche width (TNW) of Roughgarden (1972); $p=$ significance level after 999 permutations.

\begin{tabular}{|c|c|c|c|c|}
\hline & \multicolumn{2}{|r|}{ April } & \multicolumn{2}{|r|}{ June } \\
\hline & $\begin{array}{c}\text { Prey } \\
\text { availability }\end{array}$ & $\begin{array}{l}\text { Stomach contents } \\
\qquad(n=27)\end{array}$ & $\begin{array}{c}\text { Prey } \\
\text { availability }\end{array}$ & $\begin{array}{l}\text { Stomach contents } \\
\qquad(n=22)\end{array}$ \\
\hline \multicolumn{5}{|l|}{ Aquatic taxa } \\
\hline Nematoda & 8 & 1 & 6 & 0 \\
\hline Turbellaria & 0 & 0 & 0 & 10 \\
\hline Oligochaeta & 0 & 0 & 1 & 0 \\
\hline Gasteropoda & 3 & 5 & 4 & 3 \\
\hline Acarians & 10 & 2 & 15 & 0 \\
\hline Anostraca & 0 & 1 & 0 & 0 \\
\hline Ostracoda & 0 & 2 & 0 & 0 \\
\hline Isopoda & 0 & 0 & 1 & 1 \\
\hline Chironomidae larvae & 43 & 60 & 19 & 34 \\
\hline Chironomidae pupae & 3 & 2 & 2 & 5 \\
\hline Coleoptera larvae & 0 & 2 & 2 & 1 \\
\hline Diptera larvae & 1 & 1 & 2 & 19 \\
\hline Ephemeroptera larvae & 0 & 2 & 6 & 1 \\
\hline Heteroptera & 2 & 9 & 1 & 1 \\
\hline Tricoptera larvae & 7 & 6 & 5 & 4 \\
\hline Odonata nymphs & 3 & 1 & 6 & 5 \\
\hline Newt eggs & 0 & 8 & 0 & 2 \\
\hline \multicolumn{5}{|l|}{ Terrestrial taxa } \\
\hline Diplopoda & 0 & 2 & 1 & 0 \\
\hline Aranea & 0 & 2 & 2 & 2 \\
\hline Aphidoidea & 0 & 2 & 0 & 16 \\
\hline Diptera adults & 2 & 5 & 3 & 12 \\
\hline Hymenoptera flying adults & 0 & 0 & 1 & 0 \\
\hline Hymenoptera Formicidae & 4 & 0 & 1 & 0 \\
\hline Ortoptera & 0 & 8 & 1 & 0 \\
\hline Total abundance & 86 & 121 & 79 & 116 \\
\hline Shannon's $H^{\prime}$ & 1.74 & 2.01 & 2.46 & 2.16 \\
\hline $95 \% \mathrm{CL}$ & $1.42-1.93$ & $1.66-2.18$ & $2.12-2.54$ & $1.93-2.26$ \\
\hline$O_{j k}$ overlap index & 0.94 & 0.63 & & \\
\hline IS (individual specialisation index) & - & 0.47 & - & 0.40 \\
\hline$p \neq$ null distribution & & $>0.33$ & & $<0.006$ \\
\hline
\end{tabular}


There was a striking difference in the population feeding strategy between April and June samples. The population's IS was not different from the null model in April $(p=0.332$, after 999 permutations) suggesting that the entire newt population behaved as a generalist predator (Fig. 1). In June, however, the population's IS index indicated a shift towards a more specialist feeding strategy (difference from the null model, $p<0.006$, after 999 permutations; Fig. 1 and Table 2).

When the diet of the 15 newts captured both in April and June was analysed, the mean number of prey items found in their stomachs was lower in April (mean $=3.53, \mathrm{SD}=0.38)$ as compared with that in June (mean $=5.20, \mathrm{SD}=$ 0.87 ), but this difference was not significant (Wilcoxon test: $z=1.37, p=0.17$ ), and there was no significant difference when values for males and females were tested separately (Wilcoxon test: $z=1.71, p=0.09$ and $z=0, p=1$, for males and females, respectively). The individual PSi values for the 15 newts captured in April and June showed that 9 individuals shifted from a generalist to a specialist feeding pattern (Table 3), and this pattern was significant between months (Wilcoxon-paired test: $z=2.33$, $p=0.02$ ) but not when values for males and females were tested separately (Wilcoxon test: $z=1.82, p=0.07$ and $z=0.35, p=0.18$, for males and females, respectively).

\section{Discussion}

Our analysis of Alpine newt population feeding strategies gave a clear answer to our first question, concerning the relationship between individual specialization and variation in diversity of available prey. Indeed, the feeding strategy of the newt population clearly changed from generalist in April, when prey diversity was low, towards specialist in June, when available resources were more diverse. This conclusion is based on the data obtained from 15 newts caught in April and recaptured in June.

We found no differences in feeding strategies between males and females. This finding contradicts the results of Kopeky et al. (2012) and was somehow surprising to us. However, the absence

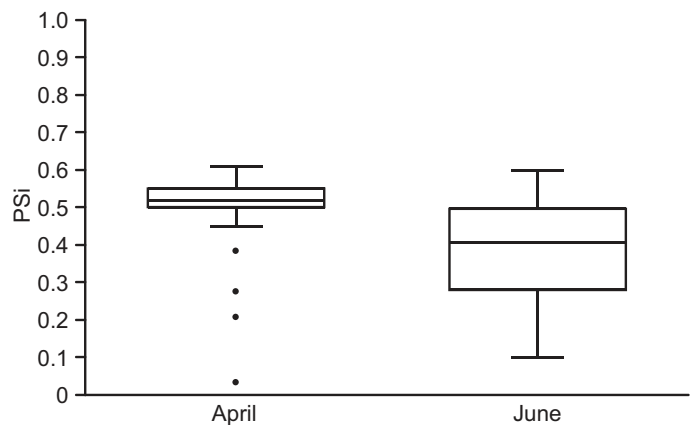

Fig. 1. Box-and-whiskers plot of individual specialization index (PSi) for the same individual newts Ichthyosaura alpestris sampled both in April and June. Median: horizontal line inside the box, box: $25-75$ quartiles; whiskers: values up to 1.5 times the box height, dots: outliers. Lower Psi values correspond to a higher individual specialisation.

of differences between sexes was based on relatively small samples (only 8 males and 7 females were recaptured; cf. Table 3) and, therefore, it should be studied further on larger samples.

Other findings of our study were that the overall population trophic niche width (TNW) did not change from April to June, while the individual feeding strategy as measured by the PSi did, i.e., a population composed mostly of generalists in April became a population of specialists in June (cf. Fig. 1). This change was caused by a shift in individual feeding behaviour that occurred in a relatively short time (i.e., less than 40 days). There may be several reasons for this shift. For example, increased prey diversity in June. This is not surprising because freshwater Mediterranean ecosystems are greatly affected by seasonality and, in particular, in standing waters macroinvertebrate diversity usually peaks by the end of spring (e.g., Trigal et al. 2007). This pattern is in agreement with previous

Table 2. Results of two-way PERMANOVA on April and June newt prey composition samples.

\begin{tabular}{lrrrcc}
\hline Source & SS & d.f. & MSS & $F$ & $p$ \\
\hline Month & 2.358 & 1 & 2.359 & 9.600 & 0.0001 \\
Sex & 0.341 & 1 & 0.341 & 1.389 & 0.178 \\
Sex $\times$ month & 0.255 & 1 & 0.254 & 1.036 & 0.092 \\
Residual & 10.812 & 44 & 0.246 & & \\
Total & 13.766 & 47 & & & \\
\hline
\end{tabular}


studies showing that an increase in prey diversity enhances trophic-niche variation within and among populations of predators (e.g., Araujo \& Costa-Perreira 2013, Sánchez-Hernández et al. 2017). Therefore, during a high prey diversity period, newt individuals actively search for and capture the most beneficial or energetic prey categories found in their habitats, which is in agreement with optimal foraging strategy (Stephens et al. 2007). In fact, newt individuals differed in their feeding behaviour by selecting different prey categories, thus increasing individual niche variation (Table 1). Finally, when the individual feeding strategies of the recaptured newts were analysed, it became evident that several of them were capable of rapid shift from generalist to a more specialist feeding behaviour by consuming only few prey categories, when prey diversity in the environment was high. This occurred without an observable change in the number of prey items captured per individual and apparently there was no difference in feeding behaviour between sexes.

This is not the first case of intra-population variation in feeding habits found in amphibians, because similar was already observed in the terrestrial cave salamander Speleomantes strinatii (Salvidio et al. 2015). However, there are two main differences between these two cases: in the terrestrial system studied by Salvidio et al. (2015), the population trophic-niche width varied being greater in autumn and smaller in spring, while the population remained specialized at the individual level in both seasons. In the aquatic newt population analysed here, however, the trophic niche width remained constant, while the overall population feeding strategy changed from generalist to specialist in a very short time, a finding that is remarkable both from behavioural and ecological points of view. The mechanisms of the observed shift in population feeding strategy were investigated by comparing trophic niches of the same newt individuals captured in April and recaptured in June. In fact, the majority of individuals shifted from generalist to specialist, sometimes displaying a striking difference in PSi values between April and June ( $>|0.20|$; cf. Table 3$)$. These results indicate that individual newts are able to change their feeding behaviour within the same season. This change may be caused by active selection of the hunting microhabitat or by active selection of different prey categories, or both (e.g., Woo et al. 2007, Terraube et al. 2014). In our current study, the newt habitat was rather homogeneous (a tank holding water for irrigation) and, there-

Table 3. Individual percent similarity values (PSi) of the same individual newts captured in April and recaptured in June. The threshold values corresponding to a specialized strategy were 0.49 and 0.47 for April and June, respectively (cf. Material and methods).

\begin{tabular}{|c|c|c|c|c|c|}
\hline \multirow{2}{*}{$\begin{array}{l}\text { Newt } \\
\text { number }\end{array}$} & \multirow[t]{2}{*}{ Sex } & \multicolumn{2}{|c|}{$\mathrm{PSi}$} & \multirow[t]{2}{*}{ Difference } & \multirow[t]{2}{*}{ Direction of change in trophic strategy } \\
\hline & & April & June & & \\
\hline 1 & male & 0.52 & 0.11 & 0.40 & generalist to specialist \\
\hline 2 & male & 0.38 & 0.38 & 0.00 & no change \\
\hline 4 & male & 0.54 & 0.48 & 0.06 & no change \\
\hline 6 & male & 0.50 & 0.54 & -0.04 & no change \\
\hline 8 & male & 0.57 & 0.24 & 0.33 & generalist to specialist \\
\hline 15 & male & 0.50 & 0.54 & -0.04 & no change \\
\hline 16 & male & 0.52 & 0.13 & 0.39 & generalist to specialist \\
\hline 17 & male & 0.54 & 0.30 & 0.24 & generalist to specialist \\
\hline 18 & female & 0.52 & 0.27 & 0.25 & generalist to specialist \\
\hline 26 & female & 0.58 & 0.41 & 0.17 & generalist to specialist \\
\hline 29 & female & 0.54 & 0.51 & 0.03 & no change \\
\hline 30 & female & 0.57 & 0.13 & 0.44 & generalist to specialist \\
\hline 31 & female & 0.52 & 0.47 & 0.04 & generalist to specialist \\
\hline 33 & female & 0.52 & 0.46 & 0.06 & generalist to specialist \\
\hline 37 & female & 0.21 & 0.52 & -0.31 & specialist to generalist \\
\hline
\end{tabular}


fore, a shift resulting from microhabitat selection seems rather improbable, while selective exploitation of different prey types is more convincing. Overall, these findings are in good agreement with the optimal foraging theory, predicting that individual predators will become more selective towards the more beneficial prey, especially during favourable periods when resource diversity is high (Stephens \& Krebs 1978, Stephens et al. 2007).

Although two of the possible mechanisms causing the observed shift in feeding behaviour were analysed (i.e. the variation in resource diversity and the individual behavioural response to this change), two more factors could also be acting in the study system. The first one is the newt population density, a factor that may affect the feeding strategy of an individual by increasing intra-specific competition for resources available in the shared habitat is observed (Stephens \& Krebs 1978, Svanbäck \& Bolnick 2007, Svanbäck et al. 2011). The second factor that could produce the observed shift is the decrease in abundance of Chiromidae larvae (i.e., main prey category) from April to June. Rarefaction of this prey category could also increase intraspecific competition among individuals foraging for this prey type. Unfortunately we do not have data on newt densities in the two sampling periods and, hence, the possible interaction between variation in trophic resources and predator density in the study ecosystem remains to be tested.

\section{Acknwoledgments}

Newts were captured under permit $0042466 / \mathrm{PNM}$ issued by the Italian Ministry of Environment. Thanks are due to the managing Editor and two anonymous Reviewers that with their constructive comments improved a previous version of this manuscript.

\section{References}

Anderson, M. J. 2001: A new method for non-parametric multivariate analysis of variance. - Austral Ecology 26: $32-46$.

Andreone, F., Tripepi, S. \& Vanni, S. 2007: Mesotriton alpestris (Laurenti, 1768). — In: Lanza, B., Andreone, F., Bologna, M. A., Corti, C. \& Razzetti, E. (eds.), Fauna d'Italia - Amphibia: 254-265. Edizioni Calder- ini, Bologna, Italia.

Andreone, F. \& Doré, B. 1992: Adaptations of the reproductive cycle in Triturus alpestris (Laurenti, 1768) to an unpredictable habitat. - Amphibia-Reptilia 13: 251261.

Araújo, M. S., Bolnick, D. I., Martinelli, L. A., Giaretta, A. A. \& dos Reis, S. F. 2009: Individual-level diet variation in four species of Brazilian frogs. - Journal of Animal Ecology 78: 848-856.

Araújo, M. S., Bolnick, D. I. \& Layman, C. A. 2011: The ecological causes of individual specialisation. - Ecology Letters 14: 948-958.

Araújo, M. S. \& Costa-Pereira, R. 2013: Latitudinal gradients in intraspecific ecological diversity. - Biology Letters 9: 20130778, http://dx.doi.org/10.1098/rsbl.2013.0778.

Bolnick, D. I., Yang, L. H., Fordyce, J. A., Davis, J. M. \& Svanbäck, R. 2002: Measuring individual-level resource specialization. - Ecology 83: 2936-2943.

Bolnick, D. I., Svanbäck, R., Fordyce, J. A., Yang, L. H., Davis, J. M., Hulsey, C. D. \& Forister, M. L. 2003: The ecology of individuals: incidence and implications of individual specialization. - The American Naturalist 161: 1-28.

Costa, A., Salvidio, S., Posillico, M., Altea, T., Matteucci, G. \& Romano, A. 2014: What goes in does not come out: different non-lethal dietary methods give contradictory interpretation of prey selectivity in amphibians. Amphibia-Reptilia 35: 255-262.

Costa, A., Salvidio, S., Posillico, M., Matteucci, G., De Cinti, B. \& Romano, A. 2015: Generalisation within specialization: inter-individual diet variation in the only specialized salamander in the world. - Scientific Reports 5: 13260, https://doi.org/10.1038/srep13260.

Crovetto, F., Romano, A. \& Salvidio, S. 2012: Comparison of two non-lethal methods for dietary studies in terrestrial salamanders. — Wildlife Research 39: 266-270.

da Rosa, I., Canavero, A., Maneyro, R. \& Camargo, A. 2011: Trophic niche variation and individual specialization in Hypsiboas pulchellus (Duméril and Bibron, 1841) (Anura, Hylidae) from Uruguay. — South American Journal of Herpetology 6: 98-106.

Denoël, M. \& Andreone, F. 2003: Trophic habits and aquatic microhabitat use in gilled immature, paedomorphic and metamorphic Alpine newts (Triturus alpestris apuanus) in a pond in central Italy. - Belgian Journal of Zoology 133: 95-102.

Denoël, M., Schabetsberger, R. \& Joly, P. 2004: Trophic specialisations in alternative heterochronic morphs. Naturwissenschaften 91: 81-84.

Devictor, V., Clavel, J., Julliard, R., Lavergne, S., Mouillot, D., Thuiller, W., Venail, P., Villéger, S. \& Mouquet, N. 2010: Defining and measuring ecological specialization. - Journal of Applied Ecology 47: 15-25.

Fasola, M. 1993: Resource partitioning by three species of newts during their aquatic phase. - Ecography 16: 73-81.

Ferner, J. W. 2010: Measuring and marking post-metamorphic amphibians. — In: Dodd, C. K. Jr. (ed.), Amphibian ecology and conservation - a handbook of techniques: 123-141. Oxford University Press, Oxford. 
Fraser, D. F. 1976: Coexistence of salamanders in the genus Plethodon: a variation of the Santa Rosalia theme. Ecology 57: 238-251.

Kopekẏ, O., Vojar, J., Susta, F. \& Rehák, I. 2012: Composition and scaling of male and female Alpine newt (Mesotriton alpestris) prey, with related size and seasonal effects. - Annales Zoologici Fennici 49: 231-239.

Lejeune, B., Sturaro, N., Lepoint, G. \& Denoël, M. 2018: Facultative paedomorphosis as a mechanism promoting intraspecific niche differentiation. - Oikos 127: $427-439$

Novak, M. \& Tinker, M. T. 2015: Timescales alter the inferred strength and temporal consistency of intraspecific diet specialization. - Oecologia 178: 61-74.

Pagani-Núnez, E., Barnett, C. A., Gu, H. \& Goodale, E. 2016: The need for new categorizations of dietary specialism incorporating spatio-temporal variability of individual diet specialization. - Journal of Zoology 300: 1-7.

Pianka, E. R. 1973: The structure of lizard communities. Annual Review of Ecology and Systematics 4: 53-74.

Romano, A., Salvidio, S., Mongillo, D. \& Olivari, S. 2014: Importance of a traditional irrigation system in amphibian conservation in the Cinque Terre National Park (NW Italy). - Journal for Nature Conservation 22: 445-452.

Roughgarden, J. 1972. Evolution of niche width. - The American Naturalist 106: 683-718.

Salvidio, S., Oneto, F., Ottonello, D., Costa, A. \& Romano, A. 2015: Trophic specialisation at the individual level in a terrestrial generalist salamander. - Canadian Journal of Zoology 93: 79-83.

Sánchez-Hernández, J. 2014: Disentangling prey-handling efficiency of larval newts through multivariate prey trait analysis. - Journal of Natural History 48: 1957-1969.

Sánchez-Hernández, J., Gabler, H.-M. \& Amundsen, P.-A. 2017: Prey diversity as a driver of resource partitioning between river-dwelling fish species. - Ecology Evolution 7: 2058-2068.

Schabetsberger, R. \& Jersabek, C. D. 1995: Alpine newts (Triturus alpestris) as top predators in a high-altitude karst lake: daily food consumption and impact on the copepod Arctodiaptomus alpinus. — Freshwater Biol- ogy 33: 47-61.

Schriever, T. A. \& Williams, D. D. 2013: Ontogenetic and individual diet variation in amphibian larvae across an environmental gradient. - Freshwater Biology 58: 223-236.

Siegel S. \& Castellan N. J. 1988. Nonparametric statistics for the behavioral sciences. - McGraw-Hill,New Yark.

Solé, M. \& Rödder, D. 2010: Dietary assessment of adult amphibians. - In: Dodd, C. K. Jr. (ed.), Amphibian ecology and conservation - a handbook of techniques: 167-184. Oxford University Press, Oxford.

Stephens, D. W. \& Krebs, J. R. 1986: Foraging theory. Princeton University Press, Princeton, NJ.

Stephens, D. W., Brown, J. S. \& Ydenberg, R. C. 2007: Foraging behaviour and ecology. - The University of Chicago Press, London.

Svanbäck, R. \& Bolnick, D. I. 2007: Intraspecific competition drives increased resource use diversity within a natural population. - Proceedings of the Royal Society of London B 274: 839-844.

Svanbäck, R., Rydberg, C., Leonardsson, K. \& Englund, G. 2011: Diet specialization in a fluctuating population of Saduria entomon: a consequence of resource or forager densities? - Oikos 120: 848-854.

Terraube, J., Guixé, D. \& Arroyo, B. 2014: Diet composition and foraging success in generalist predators: Are specialist individuals better foragers? - Basic and Applied Ecology 15: 616-624.

Trigal, C., Garcia-Criado, F. \& Fernández-Aláez, C. 2005: Among-habitat and temporal variability of selected macroinvertebrate based metrics in a Mediterranean shallow lake (NW Spain). - Hydrobiologia 563: 371-384.

Vignoli, L., Bombi, P., D’Amen, M. \& Bologna, M. A. 2007: Seasonal variation in the trophic niche of a heterochronic population of Triturus alpestris apuanus from the southwestern Alps. - Herpetological Journal 17: 183-191.

Woo, K. J., Elliott, H., Davidson, M., Gaston, A. J. \& Davoren, G. K. 2007: Individual specialization in diet by a generalist marine predator reflects specialization in foraging behaviour. - Journal Animal Ecology 77: 1082-1091. 